\title{
CLINICAL AND HISTOPATHOLOGICAL CORRELATION OF ORAL SUBMUCOUS FIBROSIS- AN INSTITUTIONAL STUDY
}

\author{
Mohammed Abidullah'1, G. Kiran Kumar², Hani Mawardi', Yagoub Alyami', Shaik Mohammed Arif5, YousufQureshi ${ }^{6}$ \\ 1Ph.D Student, Department of Oral Pathology \& Microbiology, Pacific Academy of Higher Education \& Research University, \\ Pacific University, Pacific Hills, Airport Road, Pratap Nagar Extension, Debari, Udaipur, Rajasthan. \\ ${ }^{2}$ Associate Professor, Department of Oral Pathology and Microbiology, Government Dental College, Hyderabad, Telangana. \\ ${ }_{3}^{3}$ Oral Medicine \& Periodontist, Assistant Professor, Department of Oral and Diagnostic Sciences, King Abdul Aziz University, \\ Jeddah, Saudi Arabia. \\ ${ }^{4}$ Orofacial Pain Specialist, Al-Farabi Dental College, Jeddah, Saudi Arabia. \\ ${ }^{5}$ Senior Lecturer, Department of Oral Surgery, CKS Teja Dental College and Hospital, Tirupati, Andhra Pradesh. \\ ${ }^{6}$ Senior Lecturer, Department of Oral Surgery, Malla Reddy Institute of Dental Sciences, Hyderabad, Telangana.
}

\begin{tabular}{l}
\hline ABSTRACT \\
BACKGROUND \\
Areca nut is the chief aetiologic agent of oral submucous fibrosis. This condition is categorised based on clinical and histological \\
parameters. \\
The aim of the study was to correlate the clinical and histopathological grading in oral submucous fibrosis patients.
\end{tabular}

The aim of the study was to correlate the clinical and histopathological grading in oral submucous fibrosis patients.

\section{MATERIALS AND METHODS}

Ours was a descriptive study on 100 oral submucous fibrosis cases reported to a college in Hyderabad from June 2013 to May 2014. After obtaining consent, comprehensive history was taken and a regular clinical assessment was done. Punch biopsy was made over the lesional area and histopathological assessment was done. Based on the mouth opening, patients were clinically graded [Ranganathan and Gauri (2006)] and compared with that of histopathological grading based on Sirsat and Pindborg (1966).

\section{RESULTS}

More number of males were observed (5.7: 1). Correlation between the clinical and histopathological grading was insignificant.

\section{CONCLUSION}

In oral submucous fibrosis, different parameters are used for grading it clinically and histopathologically, hence insignificant correlation between them.

\section{KEYWORDS}

Areca Nut, Betel Quid, Clinical Staging, Gutkha, Histopathological Grading, Oral Submucous Fibrosis.

HOW TO CITE THIS ARTICLE: Abidullah M, Kumar GK, Mawardi H, et al. Clinical and histopathological correlation of oral submucous fibrosis- an institutional study. J. Evolution Med. Dent. Sci. 2018;7(18):2227-2230, DOI: 10.14260/jemds/2018/501

\section{BACKGROUND}

Oral submucous fibrosis (OSMF) is a potentially malignant condition, which mainly affects oral cavity and is related to the areca nut usage in different forms. ${ }^{1}$ It is chiefly seen in Indian subcontinent. ${ }^{2}$ Studies revealed that the aetiologic agents of OSMF are areca nut consumption, chillies, nutritional deficiencies and genetic susceptibility. ${ }^{3-5}$

Initially patients suffer with burning sensation of oral mucosa, especially after taking spicy foods, blanching of affected mucosa is seen and in later stages fibrous bands observed along with trismus. ${ }^{6}$ Histopathological examination reveals atrophic epithelium along with fibroelastic alterations of the connective tissue. ${ }^{7}$ Various studies showed about 7 $13 \%$ malignant transformation. ${ }^{8}$

'Financial or Other Competing Interest': None.

Submission 19-03-2018, Peer Review 11-04-2018,

Acceptance 18-04-2018, Published 30-04-2018.

Corresponding Author:

Dr. G. Kiran Kumar,

Associate Professor

Department of Oral Pathology and Microbiology,

Government Dental College,

Hyderabad, Telangana,

India.

E-mail: kiran.dentist@gmail.com

DOI: $10.14260 /$ jemds $/ 2018 / 501$

\section{(c) (1) $(\Theta$}

Various classifications exist to grade OSMF clinically and histopathologically. ${ }^{9}$ Till now only few studies correlated the stages. Very few studies have been carried out to compare clinical and histopathological stages of OSMF, that too in Hyderabad, where this condition is highly prevalent. Ours is the first such study in Hyderabad with an aim to correlate the clinical and histopathological grading in OSMF patients for better understanding of the prognosis of this multifactorial crippling disease.

\section{MATERIALS AND METHODS Study Design and Source of Data}

We carried a descriptive study on 100 consecutive cases of clinically manifested OSMF reported to a college in Hyderabad from June 2013 to May 2014. Ethical committee clearance was acquired from the institute and also informed consent from all the subjects. A detailed case history was recorded. On basis of clinical findings, OSMF was diagnosed and was confirmed by punch biopsy and histopathological examination. We followed histological grading criteria of Pindborg and Sirsat (1966) (Fig. 1) and clinically staging of Ranganathan and Gauri (2006). ${ }^{9}$

Clinical parameters assessed were mouth opening, i.e. distance in mm between upper and lower incisal edges and blanched oral mucosa. The various stages of Ranganathan and Gauri (2006) are- 
1. Group I: Symptoms only with no definite constraint of mouth opening.

2. Group II: Mouth opening of $20 \mathrm{~mm}$ or more.

3. Group III: Mouth opening of less than $20 \mathrm{~mm}$.

4. Group IV: OSMF in advanced stages along precancerous or cancerous changes.

Histological parameters used were the type of epithelium (Para or Orthokeratinised; atrophic or hyperplastic; mild, moderate or severe dysplasia), connective tissue changes (fibrous tissue-loose or dense, inflammation type). Based on the above parameters the histological grading was given as very early, early, moderately advanced and advanced. ${ }^{9}$

\section{Habits were grouped as-}

1. Areca/ Betel nut.

2. Betel quid: Consists of betel leaf, lime, areca nut and tobacco.

3. Gutkha: Commercially available sachets with tobacco, areca nut, slaked lime and sweetening or flavouring agents.

\section{Statistical Analysis}

The observed data were tabulated and analysed using SPSS (Statistical Package for Social Science) version 16.0. The mean age difference was calculated by student t-test and chisquare test was carried out to find the association between variables. $\mathrm{P}<0.05$ was considered as significant.

\section{RESULTS}

\section{We could observe the following findings-}

1. Gender: We noticed male predominance (85\%) with 5.7:1 ratio.

2. Correlation of age with gender (Table 1) was significant $(\mathrm{p}=0.035)$.

3. When habits and gender was correlated (Table 2), it was significant $(\mathrm{p}=0.0804)$.

4. When gender and clinical staging was correlated (Table $3)$, it was significant $(\mathrm{p}=0.038)$.

5. When gender and histopathological grading was correlated (Table 4), it was significant $(p=0.0422)$.

6. Comparison of clinical staging and histopathological grading. In 68 cases of clinical grade II OSMF, 2, 8, 18 and 40 belonged to histological grades I, II, III and IV respectively. Whereas in 24 cases of clinical grade III OSMF, 1, 3, 6 and 14 belonged to histological grades I, II, III and IV respectively. The correlation was insignificant (chi-square test: $\mathrm{p}=0.925$ ).

\begin{tabular}{|c|c|c|c|c|}
\hline $\begin{array}{c}\text { Age Group } \\
\text { (Years) }\end{array}$ & Male (n) & Female (n) & Total (n) & P value \\
\hline $20-24$ & 17 & 1 & 18 & \\
\hline $25-29$ & 24 & 6 & 30 & \\
\hline $30-34$ & 18 & 2 & 20 & \multirow{2}{*}{$\mathrm{P}=0.35$} \\
\hline $35-39$ & 15 & 2 & 17 & \\
\hline$>40$ & 11 & 4 & 15 & \\
\hline Total & $\mathbf{8 5}$ & $\mathbf{1 5}$ & $\mathbf{1 0 0}$ & \\
\hline
\end{tabular}

\begin{tabular}{|c|c|c|c|c|}
\hline Habits (n= 75) & Male & Female & Total & P value \\
\hline Betel nut & 8 & 2 & 10 & \\
\cline { 1 - 4 } Betel quid & 24 & 5 & 29 & \multirow{2}{*}{0.804} \\
\hline Gutkha & 53 & 8 & 61 & \\
\cline { 1 - 4 } Total & $\mathbf{8 5}$ & $\mathbf{1 5}$ & $\mathbf{1 0 0}$ & \\
\hline \multicolumn{5}{r}{ Table 2. Habits vs. Gender } \\
\hline
\end{tabular}

\begin{tabular}{|c|c|c|c|c|c|c|}
\hline Gender & Stage 1 & Stage 2 & Stage 3 & Stage 4 & Total & $\begin{array}{c}\text { P } \\
\text { value }\end{array}$ \\
\hline Male & 5 & 60 & 18 & 2 & 85 & \multirow{2}{*}{0.38} \\
Female & 1 & 8 & 6 & - & 15 & \\
\hline Total & $\mathbf{6}$ & $\mathbf{6 8}$ & $\mathbf{2 4}$ & $\mathbf{2}$ & $\mathbf{1 0 0}$ & \\
\hline \multicolumn{6}{|c|}{ Table 3. Gender vs. Clinical Staging } \\
\hline
\end{tabular}

\begin{tabular}{|c|c|c|c|c|c|c|}
\hline Gender & Stage 1 & Stage 2 & Stage 3 & Stage 4 & Total & $\begin{array}{c}\text { P } \\
\text { value }\end{array}$ \\
\hline Male & 2 & 11 & 24 & 48 & 85 & \\
\hline Female & 1 & 3 & 5 & 6 & 15 & \multirow{2}{*}{0.422} \\
\hline Total & $\mathbf{3}$ & $\mathbf{1 4}$ & $\mathbf{2 9}$ & $\mathbf{5 4}$ & $\mathbf{1 0 0}$ & \\
\hline \multicolumn{7}{|c|}{ Table 4. Gender vs. Histological Staging } \\
\hline
\end{tabular}

\begin{tabular}{|c|c|c|}
\hline Clinical Grade & Histological Grades I, II, III, IV & Total \\
\hline I & $-24-$ & 6 \\
\hline II & 281840 & 68 \\
\hline III & 13614 & 24 \\
\hline IV & $-11-$ & 2 \\
\hline Total & $\mathbf{3 1 4 2 9 5 4}$ & $\mathbf{1 0 0}$ \\
\hline
\end{tabular}

Table 5. Distribution of OSMF Patients according to Clinical and Histological Grades

Chi-square test was done and the association was not found to be statistically significant $(p=0.925)$.

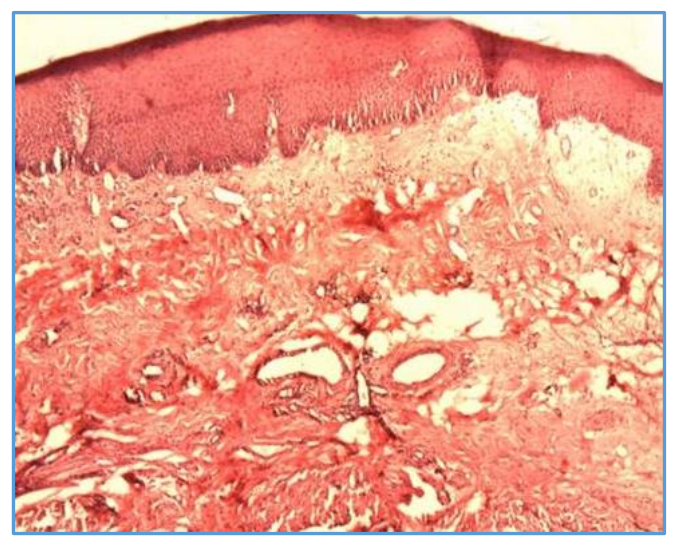

Figure 1. Moderately Advanced OSMF

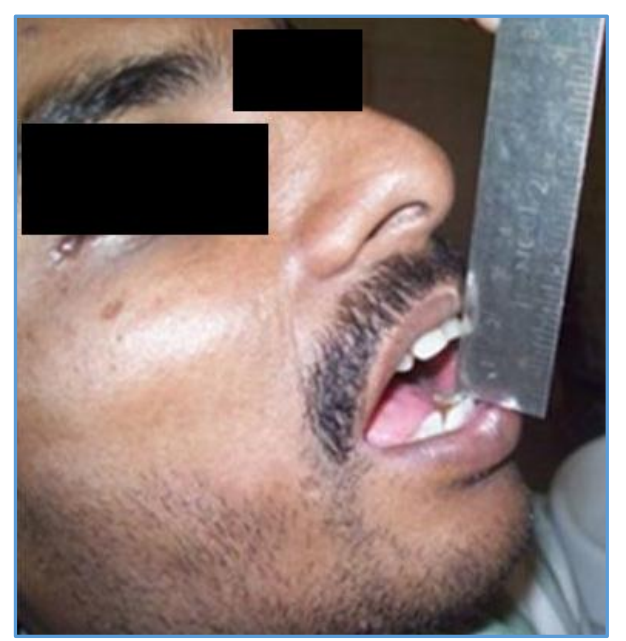

Figure 2. Clinical Grade III.jpg

\section{DISCUSSION}

OSMF is a progressive, crippling lesion of oral mucosa with altered collagen metabolism seen primarily in Indian subcontinent. ${ }^{10}$ Its occurrence in this particular geographical area is thought to be due to the usage of using betel nut and 
betel quid. ${ }^{11}$ Sushruta mentioned a lesion resembling OSMF as "Vidari."12

Its aetiopathogenesis was thought to be related to the alkaloid and arecoline of areca nut, that is proved to increase the collagen deposition juxtaepithelially.13,14

We carried our study on 100 clinically diagnosed OSMF subjects to correlate various habits and OSMF and also to correlate clinical and histological grading of OSMF. The male preponderance (5.7: 1) seen was similar to many other studies, as generally males are earners in these particular areas and have easy access to consume areca nut and females with social constraints and aesthetic consciousness generally do not consume areca nut or gutkhas. ${ }^{15-17}$

Most of our cases (30) were in younger individuals (between 25 - 29 years). This was similar to Goel et al and Katharia and Maher.16,18 However Pindborg et al showed majority of their cases between $40-49$ years. ${ }^{19}$ This change in occurrence in younger individuals may possibly owe to increasing availability and marketing through advertisement of gutkhas and pan masalas. Moreover, youth are consuming these to relieve stress and also for fashion and economic liberty in younger individuals could also be a contributing aspect. 16

OSMF was related with all varieties of areca nut. We found majority patients were consuming gutkha (61) followed by betel quid (29) and betel nut (10). This may perhaps be owed to accessibility of attractive, hand packed gutkha sachets and media ads for these products.

OSMF occurs all over the oral cavity, the commonest site being buccal mucosa followed by soft palate and uvula region. We found majority cases occurred in buccal mucosa $(60 \%)$ and soft palate (22\%). Our findings were in agreement with ABN Rao, Pindborg and Kiran et al.10,16,17

A statistically insignificant $(p=0.925)$ correlation between clinical and histological grades was seen, which might be due to these grading systems using parameters that are independent of each other. The parameters influencing clinical grading are- amount of mouth opening, degree of fibrosis and the site of the lesion, while histological grading is based on the degree of hyalinisation and collagen bundles thickness and arrangement. Our findings are similar to Koshti and Barpande (2007) and Kiran Kumar et al (2007), Goel et al (2010) and Kiran G et al (2013).1,3,10,16,20 On the other hand, we noticed that with the increase of clinical grade, more patients were in advanced histological grade.

We found majority patients were of clinical stage II (68) and histopathological grading IV (54). Our results are similar to those of Rooban et al. ${ }^{9}$ This may be due to the likelihood of a disparity in the severity and degree of fibrosis in diverse sites of the oral mucosa and involved muscles were believed as contributing factors for the discrepancy. ${ }^{21}$

\section{CONCLUSION}

Correlation of clinical staging and histopathological grading may be a useful marker for predicting the prognosis and severity of this crippling disease with malignant potential. Future studies should be done on a larger sample and also concentrate on aetiopathogenic factors like genetics, immunology and nutrition factors of OSMF.

\section{REFERENCES}

[1] KiranKumar K, Saraswathi TR, Ranganathan K, et al. Oral submucous fibrosis: a clinico-histopathological study in Chennai. Indian J Dent Res 2007;18(3):10611.

[2] Neville BW, Allen CM, Damm DD, et al. Oral and maxillofacial pathology. Philadelphia: WB Saunders Company 1995: p. 291.

[3] Koshti SS, Barpande S. Quantification of plasma fibrinogen degradation products in oral submucous fibrosis. A clinicopathologic study. J Oral Maxillofac Pathol 2007;11(2):48-50.

[4] Isaac U, Issac JS, Khoso AN. Histopathologic features of oral submucous fibrosis: a study of 35 biopsy specimens. Oral Surg Oral Med Oral Pathol Oral Radiol Endod 2008;106(4):556-60.

[5] Maher R, Lee AJ, Warnakulasuriya KA, et al. Role of areca nut in the causation of oral submucous fibrosis: a case control study in Pakistan. J Oral Pathol Med 1994;23(2):65-9.

[6] Rajendran R. Oral submucous fibrosis. J Oral Maxillofac Pathol 2003;7(1):1-4.

[7] Regezi JA, Sciubba JJ, Jordan RCK. Oral pathology: Clinical pathologic correlations. $5^{\text {th }}$ edn. St. Louis: Elsevier Saunders Publication 2007: p. 102-3.

[8] Tilakaratne WM, Klinikowski MF, Saku T, et al. Oral submucous fibrosis: review on aetiology and pathogenesis. Oral Oncology 2006;42(6):561-8.

[9] Ranganathan K, Mishra G. Review: an overview of classification schemes for oral submucous fibrosis. J Oral Maxillofac Pathol 2006;10(2):55-8.

[10] Kiran G, Sekhar MM, Hunasgi S, et al. Plasma fibrinogen degradation products in betel nut chewers with and without oral submucous fibrosis. J Oral Maxillofac Pathol 2013;17(3):324-8.

[11] Ali FM, Aher V, Prasant MC, et al. Oral submucous fibrosis: comparing clinical grading with duration and frequency of habit among areca nut and its products chewers. J Can Res Ther 2013;9(3):471-6.

[12] Rao PK. Efficacy of alpha lipoic acid in adjunct with intralesional steroids and hyaluronidase in the management of oral submucous fibrosis. J Cancer Res Ther 2010;6(4):508-10.

[13] Rajalalitha P, Vali S. Molecular pathogenesis of oral submucous fibrosis - a collagen metabolic disorder. J Oral Pathol Med 2005;34(6):321-8.

[14] Debnath S, Mitra B, Paul B, et al. Morphometric analysis of oral submucous fibrosis and its correlation with histological staging and clinical severity of trismus. Egyptian Journal of Ear, Nose, Throat and Allied Sciences 2013;14(2):85-90.

[15] Ahmad MS, Ali SA, Ali AS, et al. Epidemiological and etiological study of oral submucous fibrosis among gutkha chewers of Patna, Bihar, India. J Indian Soc Pedod Prev Dent 2006;24(2): 84-9.

[16] Goel S, Ahmed J, Singh MP, et al. Oral submucous fibrosis: a clinico-histopathological comparative study in population of Southern Rajasthan. J Carcinogene Mutagene 2010;1:108. 


\section{Jemds.com}

[17] Sinor PN, Gupta PC, Murti PR, et al. A case control study of oral submucous fibrosis with special reference to the etiologic role of areca nut. J Oral Pathol Med 1990;19(2):94-8.

[18] Taneja L, Anjana B, Vaishali K. Haemoglobin levels in patients with oral submucous fibrosis. JIAOMR 2007;19(2):329-33.

[19] Pindborg JJ, Mehta FS, Daftary DK. Epithelial atypia in 51 Indian villagers with OSMF. $\mathrm{Br} \mathrm{J}$ Cancer 1970;24(2):253-7.

\section{Original Research Article}

[20] Rooban T, Saraswathi TR, Al Zainab FH, et al. A light microscopic study of fibrosis involving muscle in oral submucous fibrosis. Indian J Dent Res 2005;16(4):131-4.

[21] Pandya S, Chaudhary AK, Singh M, et al. Correlation of histopathological diagnosis with habits and clinical findings in oral submucous fibrosis. Head \& Neck Oncology 2009;1:10. 